\title{
ASSISTÊNCIA PRÉ-NATAL SOB A ÓTICA DE GESTANTES E FAMILIARES
}

\author{
PRENATAL CARE FROM THE PERSPECTIVE OF \\ PREGNANT WOMEN AND FAMILIES
}

\author{
Fabiano Fraga Carpes', Lucia Beatriz Ressel ${ }^{2}$, Karine Eliel Stumm ${ }^{3}$
}

\section{RESUMO}

Objetivo: conhecer as percepções de gestantes e familiares acerca da assistência pré-natal. Metodologia: estudo de campo, descritivo, qualitativo com abordagem cultural. Os participantes da pesquisa foram cinco gestantes que realizavam o pré-natal em consulta de enfermagem e um familiar indicado por elas. Como instrumento de coleta de dados foi utilizada a entrevista semi-estruturada, e também a observação participante, do tipo observador-como-participante. Os dados foram analisados de acordo com a análise temática. Resultados: atividades educativas como grupo de gestante foram ressaltadas como uma forma de aprendizado, compartilhamento de experiências e apreensão de orientações. Considerações finais: a participação da família contribui para a qualidade da assistência, reforçando sentimentos positivos nas gestantes, como segurança e tranquilidade.

Descritores: Enfermagem; Cuidado Pré-natal; Saúde da Mulher.

\begin{abstract}
Objective: to know the perceptions of pregnant women and family about prenatal care. Methodology: field of study, descriptive, qualitative with cultural approach. The subjects were five pregnant women who perform prenatal care in nursing consultation and family, indicated by them. As data collection instrument was used to semi-structured interview. It was also used participant observation, the type observer-as-participant. Data were analyzed according to thematic analysis. Results: educational activities such as pregnancy group with families were highlighted as a way of learning, sharing experiences and seizure guidelines. Final considerations: Family participation contributes to the quality of care reinforcing positive feelings in pregnant women, such as security and tranquility.
\end{abstract}

Descriptors: Nursing; Prenatal Care; Women's Health.
${ }^{1}$ Graduando de Enfermagem na Faculdade Cenecista de Osório (FACOS), Osório, RS, Brasil.

${ }^{2}$ Doutora em Enfermagem pela Universidade de São Paulo (USP), São Paulo, SP, Brasil.

${ }^{3}$ Mestre em Enfermagem pela Universidade Federal de Santa Maria (UFSM), Santa Maria, RS, Brasil. 


\section{Introdução}

Até a década de 80 a atenção à saúde das mulheres era centrada apenas no ciclo gravídico, tendo o pré-natal como a assistência mais oferecida ao público feminino no Brasil, compreendendo as mulheres unicamente como um corpo reprodutivo e no papel social de mãe. Com a reivindicação de direitos para uma atenção que fosse além da gestação e do parto, fez-se necessária uma avaliação das políticas de saúde vigentes, com o objetivo de melhorar a atenção à saúde das mulheres em todos os ciclos de vida².

Dessa forma, em 1984 o Ministério da Saúde criou o Programa de Assistência Integral à Saúde da Mulher (PAISM), com a finalidade de oferecer às mulheres assistência no pré-natal, parto, puerpério, clínica ginecológica, climatério, planejamento familiar, câncer de colo e de mama e DST (Doenças Sexualmente Transmissíveis) ${ }^{3}$. Além de abordar os problemas da adolescência até a terceira idade, o programa também previa em suas diretrizes uma nova postura da equipe de saúde, que deveria atuar com enfoque na atenção integral e adotar práticas educativas ${ }^{1}$. Em 2004 o Programa transformou-se em uma Política Nacional de Atenção Integral à Saúde das Mulheres, com base em diagnósticos da situação de saúde das mulheres no Brasil. Essa política significou grande avanço nos direitos reprodutivos femininos, uma vez que instituiu os princípios de qualidade e humanização da assistência à saúde das mulheres ${ }^{1}$. Na esteira da construção desta política pública, no ano de 2000, o Ministério da Saúde criou o Programa de Humanização no Prénatal e Nascimento, visando reduzir as taxas de morbimortalidade materna e perinatal, ampliar o acesso ao pré-natal, estabelecer critérios de qualificação das consultas e promover vínculo entre a assistência ambulatorial e o parto.

Entende-se que o cuidado pré-natal deve possibilitar segurança e tranquilidade à gestante, e ser estendido à família que também necessita de suporte emocional e educacional para se estruturar frente às mudanças geradas com a gestação ${ }^{4}$. Destaca-se ainda que, dentre as atividades pertinentes ao enfermeiro no desenvolvimento e acompanhamento do pré-natal estão: fazer consultas de enfermagem, solicitar exames complementares e prescrever medicações, observadas as disposições legais da profissão e conforme os protocolos ou outras normativas técnicas estabelecidas pelos gestores estaduais, municipais ou por aqueles do Distrito Federal. Essas atividades estão asseguradas na Lei do Exercício Profissional da Enfermagem (Decreto n 94.406/87) e na portaria $n^{0} 1.625$, de 10 de julho de 2007, do Ministério da Saúde ${ }^{3}$. Logo, por meio desta legislação, esse profissional está respaldado legalmente para realizar consulta de enfermagem no pré-natal, segundo protocolos pré-estabelecidos ${ }^{3}$.

É importante compreender que apesar da gestante e o bebê constituírem o foco principal do processo gestacional, é necessário promover o envolvimento e inclusão dos familiares nessa etapa. Tendo a família um destaque para além da gestação, compreendendo sua participação responsável frente às questões diversas, socioculturais e sexuais. Nesta direção, os serviços de saúde precisam estar acessíveis às mudanças sociais para efetivar a promoção e a educação em saúde 5 .

Para uma maior efetivação da inclusão da família no processo gestacional, foi instituída a Lei 11.108, de 07 de abril de 2005, que garante à parturiente, no âmbito do Sistema Único de Saúde, o direito de ter acompanhante no trabalho de parto, parto e pós-parto imediato. Nesse sentido, percebe-se esforços de tornar concreta a participação da família no período gestacional, entendendo sua importância para a formação de vínculo com o recém- nascido e suas relações posteriores.

A gestação, como um evento social, prevê a necessidade de apoio e suporte emocional do grupo no qual se encontra. Tal grupo pode envolver familiares, companheiro, amigos, vizinhos, e confere à mulher condições de maior tranquilidade e segurança no transcorrer do processo gestacional, além de contribuir para o fortalecimento das relações familiares. Ademais, a cultura da família também implica diretamente no cuidado que a gestante terá com sua saúde e com o bebê, uma vez que os hábitos de vida, valores e crenças são passados de geração a geração, e ainda de acordo com o contexto cultural em que se inserem ${ }^{6}$.

Além disso, a inclusão dos familiares, no processo gestacional, torna-se fundamental nos cuidados que serão desenvolvidos neste período, incentivando a realização das consultas, e possibilitando maior adesão da atenção à saúde na gestação ${ }^{4}$. Este sistema cultural de cuidado que envolve os familiares é chamado de cuidado familial. A família também é considerada um sistema de saúde para seus membros, uma vez que faz parte deste sistema um conjunto de valores, crenças, práticas e conhecimentos que irão guiar as ações destes familiares na promoção de saúde, e na prevenção e tratamento de doenças ${ }^{8}$.

O cuidado familial se faz presente nos grupos familiares, concretizado a partir da convivência entre seus membros, e é direcionado a cada membro familiar com o objetivo de promover seu crescimento, desenvolvimento, saúde e bem estar $^{7}$. O cuidado está intrinsecamente ligado à família, pois é nela que se aprende a cuidar e ser cuidado. 
A família tem um importante papel no processo saúde/doença de seus membros, sendo este papel desempenhado principalmente nos momentos de tomada de decisão, seja na procura por atendimento médico, quando um membro familiar apresenta algum sintoma ou mal estar, no incentivo de adesão a tratamentos, ou mesmo na avaliação e no acompanhamento da saúde e da doença ${ }^{9}$.

Geralmente, nas famílias, é a mãe quem decide e cuida do filho doente, revelando que a participação familiar no processo de cuidar está ligada a aspectos culturais, no entanto o adulto, quando se encontra adoecido, apesar de tomar suas próprias decisões quanto à adesão de tratamentos, espera que os familiares também contribuam com conselhos e opiniões. Nesse sentido, a família é um sistema cultural de cuidado à saúde, podendo vir a complementar o sistema profissional de saúde ${ }^{9}$.

Nesta direção, constituiu-se como objeto desse estudo, a vivência da família no processo gestacional. Como questão norteadora, formulou-se a seguinte pergunta: Como se dá o relacionamento pré-natal a família de gestantes assistidas em uma Unidade Sanitária, no município de Santa Maria/RS (Rio Grande do Sul)? E como objetivo do artigo conhecer as percepções de gestantes e familiares acerca da assistência pré-natal.

\section{Metodologia}

Foi realizado um estudo de campo, descritivo, qualitativo com abordagem cultural. O estudo de campo se caracteriza por focalizar uma comunidade, não necessariamente geográfica, por meio da observação direta e de entrevistas com informantes para captar suas explicações e interpretações do que ocorre no grupo ${ }^{10}$.

O estudo descritivo busca conhecer as distintas situações e relações que ocorrem na vida social, política, econômica e nos diferentes aspectos do comportamento humano, tanto isoladamente quanto em grupos e comunidades complexas ${ }^{11}$.

A abordagem qualitativa é aplicável a este tipo de pesquisa, pois, é congruente ao estudo da história, das relações e opiniões, que são produtos das interpretações a respeito de como humanos vivem, sentem e pensam ${ }^{12}$.

Os referenciais teóricos para discussão e análise dos dados foram apoiados principalmente na teoria da Interpretação das Culturas ${ }^{13}$. Este autor é representante de uma linha simbólica, assume a cultura como sendo teias de significados que o próprio homem tece, e a interpretação a busca destes significados pelo homem. Ainda, se refere à descrição densa dos acontecimentos, e que essa permite perceber que os dados destes acontecimentos passam pelo elo da significação, necessitando assim de uma interpretação. A descrição densa caracteriza-se por ser, portanto, interpretativa. Isso significa proporcionar a interpretação do fluxo do discurso social; consiste em armazenar o que é dito em um discurso e fixá-lo em formas pesquisáveis. Além disso, é microscópica, pois o antropólogo se defronta com as grandes realidades, busca retirar delas a sua essência ${ }^{13}$.

Ressalta-se que a interpretação não busca responder às questões profundas, mas sim obter as respostas que os outros dão e colocá-las à disposição de todos. Em suma, a descrição densa permite a interpretação dos significados e promove uma relação entre eles. A interpretação de cada pesquisador expressa sua própria visão de mundo, ou seja, a sua construção cultural, logo, estas interpretações não podem ser consideradas verdades absolutas, mas recortes de cada singularidade social e cultural14.

O cenário de pesquisa foi à região norte do interior de Santa Maria/RS (Rio Grande do Sul), tendo como local para captação dos participantes o consultório de enfermagem, onde são realizadas as consultas de pré-natal, em uma Unidade Sanitária.

Os participantes da pesquisa foram cinco gestantes que realizaram o pré-natal em consulta de enfermagem e um familiar indicado por elas em consultas anteriores. Logo, o número de 10 sujeitos se justificou pela metodologia deste estudo, e foi observado o momento em que os dados apresentaram saturação. Desenvolveu-se um contato prévio com as gestantes por meio das consultas de pré-natal na Unidade de Saúde, onde foi realizado o convite para a participação na pesquisa.

Os critérios de inclusão foram: gestantes e familiares indicados por elas para acompanhamento, que realizam prénatal na Unidade Sanitária; que tivessem realizado no mínimo três consultas pré-natais, a fim de que pudessem já ter alguma vivência com a gestação e o pré-natal; possuir mais de 18 anos; apresentar condições físicas de participação na pesquisa.

Os critérios de exclusão foram familiares que não residiam na zona urbana do município de Santa Maria/RS, se justifica pela área de atuação da UBS (Unidade Básica de Saúde ), na qual as gestantes fazem o programa de pré- natal.

Como instrumento de coleta de dados utilizou-se a entrevista semi-estruturada, que permite ao entrevistado discorrer sobre o tema sem respostas prefixadas pelo entrevistador ${ }^{12}$. Também foi utilizada a observação participante, do tipo observador-como-participante como estratégia complementar à entrevista. Esta modalidade de observação se dá em 
um curto espaço de tempo, na qual o pesquisador tem um contato superficial com pesquisados ${ }^{11}$. As observações foram registradas em um diário de campo e possibilitaram o registro de percepções e informações, sobre conversas informais, comportamentos e expressões relacionadas ao tema da pesquisa, que não tinham sido registrados na entrevista formal ${ }^{12}$.

Como subsídio, foi utilizado um roteiro de entrevista semi-estruturada, que serviu, tanto para a gestante, quanto para o familiar, apenas com algumas perguntas direcionadas a um ou/e outro. A entrevista semi-estruturada combina perguntas fechadas e abertas possibilitando ao entrevistado discorrer sobre o tema questionado. As entrevistas realizaram-se com a presença de ambos os participantes juntos. Os dados da coleta foram gravados em um aparelho digital e após, transcritos para análise dos pesquisadores conforme análise temática, constituindo-se de quatro etapas: pré-análise, exploração do material, tratamento dos resultados obtidos e interpretação ${ }^{11}$.

A pesquisa foi realizada em 2012, não estando vigente ainda a resolução do CNS (Conselho Nacional de Saúde) $n^{0}$ 466/12. Foram observadas as normas da Resolução n 196/96 do Conselho Nacional de Saúde do Ministério da Saúde que regem pesquisas envolvendo seres humanos, assegurando condução ética durante a investigação. Para a participação dos entrevistados, foi fornecido previamente o Termo de Consentimento Livre e Esclarecido, sendo informados individualmente acerca dos objetivos da pesquisa, dos benefícios que essa promoveria e da não obrigatoriedade de sua participação. Número CAAE (Certificado de Apresentação para Apreciação Ética): 00552812000005346.

$O$ cenário escolhido para as entrevistas foi à residência das gestantes, em data combinada com elas, e a Unidade Sanitária, em espaço apropriado, devido ao fato das gestantes já estarem ali para consulta pré-natal com o membro da família que indicaram para participação.

\section{Resultados e Discussão}

As gestantes possuíam idade entre 18 e 39 anos; quanto ao estado civil, três declararam estar casadas, e duas solteiras. Destas solteiras, uma encontrava-se separada do companheiro e a outra namorando. Das cinco gestantes entrevistadas, duas eram primigestas, as outras variaram entre quatro, dois e um filho. No tocante à religião, três referiram ser católicas, uma espírita e uma umbandista, assim como seus familiares entrevistados. A escolaridade variou entre o Ensino Fundamental e o Ensino Médio. Os membros da família, escolhidos pelas gestantes, foram mães, irmã e companheiro. Os depoimentos a seguir referem-se aos dados construídos, junto aos participantes do estudo, ao serem questionados sobre o entendimento acerca do pré-natal e a importância do mesmo. Além disso, o que aprendem nas consultas e atividades educativas, e como a família tem participado deste acompanhamento.

Em relação ao conhecimento dos participantes sobre o que é o pré-natal e sua importância eles relataram:

Pré-natal pra mim é fazer um acompanhamento, conforme vai crescendo a minha barriga ele vai crescendo. [...] as consultas com o médico que eu faço. (G1)

Eu não sei, nunca fiz. Eu engravidava e eu ia ao médico só pra ganhar. Não tive necessidade, estava sempre bem. (F2)

Pra mim é pra ti ver como que está o bebê, se ele está bem, para saber mais ou menos como é que a criança está. (G4)

É um acompanhamento, do desenvolvimento fetal até o parto. (F5)

Pra evitar doença, se a gente adoece a criança também. (F1)

Acho importantíssimo. Aquela consulta que a gente tem com o pessoal da enfermagem eu achei maravilhosa, vim de lá deslumbrada. Porque é um negócio que tu ficas sabendo muita coisa que tu não sabes, inclusive da amamentação que elas me explicaram muita coisa, que eu não conseguia amamentar, esse primeiro eu não consegui. E eu senti também que ali é como se fosse uma sala de psicologia, a gente conversa de tudo, então achei muito bom. (G2) 
Além do entendimento de pré-natal como uma ação de acompanhamento no crescimento e desenvolvimento fetal, os participantes declararam considerá-lo importante, também, em outros aspectos, como prevenção de complicações e aprendizados diversos.

Inicialmente, observa-se nos depoimentos que o pré-natal configura-se como um acompanhamento, por meio de consultas, citado por eles com o médico ou enfermeira. Este acompanhamento constitui-se, para alguns entrevistados, prioritariamente, na avaliação do bebê até o momento do parto, dissonando de outros objetivos importantes da atenção pré-natal. Para um dos familiares entrevistados, no entanto, não havia necessidade de fazer o pré-natal em seu tempo de gravidez relembrando que nunca havia realizado este acompanhamento em suas gestações. A atenção pré-natal consiste na prevenção, promoção da saúde e tratamento de problemas que ocorrem durante o processo gestacional a após o parto. É uma assistência dirigida à gestante, família e bebê, a partir do acolhimento e da compreensão dos significados da gestação para cada família ${ }^{13}$. Além disso, a ideia dos entrevistados, de que este cuidado é apenas um acompanhamento para "ver como está à criança", está fortemente relacionada à década de 70 quando ainda não existia no país a Política Nacional de Atenção Integral à Saúde da Mulher, e assim limitava-se às demandas relativas à gravidez e ao parto. Neste panorama, faz-se necessário orientar gestantes e famílias que a atenção pré-natal vai muito além do simples acompanhamento fetal, enfatizando as atividades educativas, acolhimento, acompanhamento físico e emocional da gestante, entre outros, como demais assistências prestadas ${ }^{5}$.

Ressaltou-se também nos depoimentos, a importância da atenção pré-natal como um cuidado preventivo para evitar complicações durante a gestação, para espaço de aprendizagem sobre cuidados com o bebê e sobre saúde, para acompanhar o desenvolvimento e crescimento fetal, e para promoção do bem-estar materno.

A gestação é um processo que envolve aspectos biológicos, sociais e culturais, pois está permeada de práticas que incluem mitos, crenças e hábitos acerca do cotidiano das pessoas, como sua alimentação, higiene, atividade sexual e cuidados específicos demandados pelas alterações da gravide $z^{15}$. Este fato desvela a importância do empoderamento de gestantes e familiares sobre o cuidado de si e do bebê, por meio dos grupos de gestantes e consultas de pré-natal com foco no cuidado cultural.

As entrevistadas que já tiveram filhos anteriormente, enfatizaram o fato de parecer tudo novo e estarem aprendendo muitas coisas que não sabiam com as consultas e com os grupos de gestantes:

Têm coisas que as enfermeiras estão me explicando que eu nem sabia, parece que é tudo novo, parece que é a primeira gravidez. (G3)

Nas minhas duas gestações eu fiz o pré-natal, foi importante porque tem muitas coisas que às vezes tu não sabes e tu aprendes com eles. (F4)

Aprendo no cursinho de gestantes. (G5)

Nas falas das entrevistadas identifica-se a relevância das orientações realizadas pelos enfermeiros e dos grupos de gestantes, os quais possibilitam o aprendizado sobre o desenvolvimento e crescimento fetal, alterações físicas e emocionais durante o período gestacional, e demais mudanças e cuidados a serem realizados neste processo. Enfatiza-se a importância de tais atividades educativas pelo fato de que cada gestação é única, e com ela sempre surgem dúvidas e aprendizados.

A gestante constitui foco principal de aprendizagem juntamente com seus familiares, sendo o grupo de trabalho com as gestantes uma importante atividade educativa de sociabilização de conhecimentos, onde 0 enfermeiro tem 0 papel de facilitador ${ }^{12}$.

Em relação aos conhecimentos oriundos das orientações durante as consultas de pré-natal e grupo de gestantes, os participantes do estudo ressaltaram vários cuidados ministrados pela enfermeira no acompanhamento do pré-natal:

Ali a gente vai aprendendo como é que vai fazer com a criança quando nascer, como é que cuida, como é que muda, como é que lava. [...] Eu aprendi tudo quando comecei a fazer o pré-natal dos meus filhos. (F1)

A orientação das enfermeiras, pra mim, tem sido muito válida, principalmente na amamentação porque eu não pude amamentar o meu guri. Racharam-me os seios, daí começou a secar daí não pude amamentar. Agora elas me orientaram tudo da amamentação. (G3) 
Que não pode pegar muito peso, elas "enfermeiras" falam mais das frutas, que eu tenho que cuidar com a alimentação e os exercícios. Eu fumo, mas agora estou começando a diminuir um pouco, elas começaram a falar que era pra diminuir. (G4)

No estudo é possível perceber que fala de cuidado com as recém-nascidas relacionadas à alimentação da gestante, amamentação, atividade física, tabagismo e mudanças corporais durante a gestação, foram enfatizadas por enfermeiras durante consultas de pré-natal de baixo risco e grupos de gestante.

Ressalta-se o grupo de gestantes como uma estratégia de aprendizado e trocas. Corroborando com o Ministério da Saúde, o intercâmbio de experiências e conhecimentos, facilitado por meio dos grupos de gestantes, é a melhor forma de promover a compreensão do processo gestacional ${ }^{12}$. Este espaço de compartilhamento de vivências é essencial para fomentar a participação da família, adequando às orientações, partindo dos seus conhecimentos, valores, e realidades.

Quanto à participação da família no pré-natal, os entrevistados identificaram algumas deficiências no serviço, sendo prejudiciais à qualidade deste, e implicando diretamente na sua participação:

Agora eles deixam a família participar, antigamente eles não deixavam, porque quando eu ia fazer o meu pré-natal não deixavam entrar. [...] Deviam autorizar os acompanhantes que vão junto, pelo menos o marido ou a mãe. (F1)

Na enfermagem não tem esse problema, mas no médico tem. Nas consultas não deixam entrar. 0 médico deveria deixar mais. (G1)

O médico já deixando uma pessoa ficar junto já está ótimo. Eu acho isso melhor, bem melhor. (G4)

Revela-se nos depoimentos a necessidade e importância percebida pelos participantes do estudo em relação às gestantes ser acompanhadas nas consultas de pré-natal. No entanto, a participação dados familiares ainda é tolhida por alguns profissionais de saúde. Contrapondo-se a isso se pensa que, em uma época onde os estudos, programas e políticas voltados à família, tornam-se ainda mais crescentes e revelam sua importância na vivência da gestação, fica necessário o repensar profissional na atenção à gestante e na inclusão dos seus familiares no processo gestacional.

Igualmente , destaca-se que é preciso respeitar as necessidades dos envolvidos no cuidado pré natal da gestante, incluindo-a nos serviços de atenção pré-natal a fim de fortalecer os vínculos com os profissionais de saúde, e promover 0 bem-estar dos parentes frente ao processo gestacional ${ }^{16}$. 0 cuidado singular dirigido a cada familiar valorizando seus conhecimentos, bagagem cultural, crenças e valores, incentiva as interações ao longo da trajetória da família e, estimula o bem-estar dos membros da família ${ }^{7}$.

Outro ponto abordado foi o horário das consultas de pré-natal sendo ressaltado pelos participantes como um fator inibidor para a participação da família:

Eu vou sozinha até por causa dos horários que está todo mundo trabalhando. É o horário de serviço da mãe. (G2)

A gente não tem ido com ela por causa do serviço, a gente não tem condições de participar, é questão de falta de tempo. (F2)

Todo mundo trabalha. Se eu precisar realmente, se for alguma coisa de necessidade eles vão, falham o serviço, ou deixam os filhos com alguém e vão. [...] eles fazem coisas com a família, é que às vezes a família mesmo que não pode ir. (G3)

Os entrevistados revelam que a participação da família na atenção pré-natal muitas vezes não ocorre devido ao horário das consultas, que se dá no mesmo turno de trabalho dos membros da família das gestantes. Não havendo possibilidade de escolha pelo horário ou turno do pré-natal a gestante acaba indo sozinha, tanto nas consultas, quanto nas atividades de grupo de gestante.

Enfatiza-se a importância da participação dos familiares na atenção pré-natal e nas atividades educativas, porém, isso gera a necessidade de mudanças específicas nos serviços, que possam atender de forma ampla e satisfatória, as demandas de promoção à saúde da população ${ }^{15}$. 
Nesta direção, os participantes do estudo expressam em suas falas a necessidade de maior participação da família na atenção pré-natal:

Acho que seria bom a família participar mais da gestação, acompanhar o pré-natal. Até para saber melhor, para saberem mais cuidados, para está todo mundo junto. (G2)

Acho importante a família ir, pra eles participarem, para verem. (G3)

Ébom um sempre irjunto. O pai da minha guriazinha ia sempre junto, dá segurança, ébom, ele vê também, está ali a par do crescimento porque eles medem, escutam o coraçãozinho. (F3)

É uma coisa que tu tens que ter alguém que já saiba disso sempre do teu lado. (G4)

A participação dos familiares na atenção pré-natal confere aprendizados que poderão ser levados ao núcleo familiar colaborando com a qualidade do processo gestacional e da construção sociocultural dos sujeitos envolvidos. Além disso, viabiliza sentimentos de segurança, confiança e satisfação. Conforme o relato, o acompanhamento do prénatal, pelos membros da família, constitui um significado de união, na qual a gestação passa a assumir um papel real na vida familiar e não apenas no que é falado pela gestante.

Neste sentido, pode-se entender a presença dos familiares na atenção pré-natal como elemento constitutivo do cuidado familiar, compreendendo ações, interações e interpretações de solidariedade, que a família demonstra a seus membros $^{7}$. Ademais, a participação dos familiares na atenção pré-natal pode ser compreendida como cuidado familiar que impulsiona o bem-estar dos membros familiares e a promoção de vida, favorecendo o desenvolvimento das potencialidades de cada membro, pela criação de um ambiente físico e simbólico favorável às trocas e ao crescimento grupal ${ }^{7}$.

Assim, desvela-se a importância da inclusão dos familiares na atenção pré-natal, como forma de qualificar esta atenção, considerando cada família como um grupo único e singular, repleto de crenças, valores e significados que deverão ser considerados a cada consulta promovendo o cuidado humanizado.

\section{Considerações Finais}

Observou-se neste estudo que as gestantes e seus familiares percebem na assistência pré-natal como um acompanhamento benéfico à mãe e ao bebê, e consideram importante a sua realização para melhor perceber as mudanças que ocorrem durante o processo gestacional.

É preciso compreender as necessidades de cada família de forma singular para que sua inclusão possa ser efetivada na atenção pré-natal. No entanto, a falta de tempo foi o principal motivo relatado para a dificuldade de acesso ao serviço pré-natal. A falta de flexibilidade dos horários das consultas, e da disponibilidade dos membros da família para acompanharem às gestantes devido a seus compromissos profissionais, foram os motivos destacados para o não acompanhamento nas consultas de pré-natal.

Atividades educativas, como o grupo de gestantes foram ressaltadas como uma forma de aprendizado, compartilhamento de experiências e apreensão de orientações. Nestas atividades as famílias também devem ser estimuladas e envolvidas. A participação da família pode contribuir para a qualidade da assistência reforçando sentimentos positivos nas gestantes.

\section{Referências}

1. Freitas GL, Vasconcelos CTM, Moura ERF, Pinheiro AKB. Discutindo a política de atenção à saúde da mulher no contexto da promoção da saúde. Rev.EletrônicaEnferm [Internet].2009 abr/jun 11(2):424-8. Disponível em: http://www. fen.ufg.br/revista/v12/n2/v12n2a16.htm

2. Brasil. Ministério da Saúde. Cadernos de Atenção Básica, n. 26, Saúde Sexual e Saúde Reprodutiva. Brasília; 2009.

3. Brasil. Ministério da Saúde. Relatório de Gestão 2003 a 2006: Política Nacional de Atenção Integral à Saúde da Mulher. Brasília; 2007. 
4. Zampieri MFM, Erdmann AL. Cuidado humanizado no pré-natal: um olhar para além das divergências e convergências. RevBrasSaudeMaterInfant [online] 2010;10(3):359-36. Disponivel em: http://www.scielo.br/scielo.php?script=sci_ arttext\&pid=S151938292010000300009\&Ing=en\&nrm=iso>

5. Brasil. Ministério da Saúde. Manual técnico do pré-natal e puerpério. Brasília; 2006.

6. Helman CG. Cultura, saúde e doença. Porto Alegre: Artmed; 2003.

7. Elsen I. Cuidado familial: uma proposta inicial de sistematização conceitual. In: Elsen I, Marcon SS, Santos MR. O viver em família e sua interface com a saúde e a doença. Maringá: UEM; 2002. p.11-24.

8. Elsen I. Concepts of health and illness and related behaviour among Brazilian families living in a fishing village. 1984. $301 \mathrm{f}$. Thesis (Doctorate in Nursing Science) - University of California, São Francisco, 1984.

9. Kleinman A. Patients and healers in the context of the culture: an exploration of the borderland between Anthropology, Medicine and psychiatry. California: Regents; 1980.

10. Cervo AL, Bervian PA, da Silva R. Metodologia científica. São Paulo: Pearson Pratice Hall; 2007.

11. Minayo MCS. O desafio do conhecimento: pesquisa qualitativa em saúde. 10ª ed. São Paulo: Hucitec; 2007.

12. Brasil. Ministério da Saúde. Tensão ao pré-natal de baixo risco. Caderno de atenção básica. Brasília; 2013.

13. Geertz CA interpretação das culturas. Rio de Janeiro: LTC, 2008

14. Ressel LB. Vivenciando a sexualidade na assistência de enfermagem: um estudo na perspectiva cultural. São Paulo: USP, 2003. Tese (Doutorado), Universidade de São Paulo, 2003.

15. Baruffi LM. O cuidado cultural à mulher na gestação. Passo Fundo: UPF; 2004

16. Santos AL, Radovanovic CAT, MarconSS.Assistência pré-natal: satisfação e expectativas. Rev. Rene. 2010; 11 número especial: 61-71

17. Gonçalves ITJP; Souza KV; Amaral MA, Oliveira ARS; Ferreira WFC. Prática do Acolhimento na Assistência PréNatal: Limites, Potencialidades e Contribuições da Enfermagem. Rev Rene. 2013; 14(3):620-9.

18. Alves CN, Wihelm LA,Barreto CN, Santos CC, Meincke SMK, Ressel LB; Cuidado pré-natal e cultura: uma interface na atuação da enfermagem; Escola Anna Nery Revista de Enfermagem 19(2) Abr-Jun 2015;19(2):265-271.

19. Castro ME, Moura MAV, Silva LMS; Qualidade da Assistência Pré-Natal: Uma perpectiva das Puérpias Egressas; Rev. Rene, vol. 11, Número Especial, 2010. p. 72-81

20. Duarte SJH, Mamede MV; Ações do Pré-Natal Realizadas pela Equipe de Enfermagem na Atenção Primária á Saúde, CUIABÁ; Ciência y Enfermerla XIX (1): 117-129, 2013.

21. Lima SS; Enfermagem no pré-natal de baixo risco na estratégia Saúde da Família; AÑO 13 - VOL. 13 No 2 - CHÍA, COLOMBIA - AGOSTO 2013

\section{Karine Eliel Stumm}

Endereço para correspondência - Rua: Marechal Floriano, $n^{\circ}$ 4, apto 201

Bairro: Caiu do céu , CEP: 95520-000, Osório, RS, Brasil.

E-mail: kkstumm@hotmail.com

Lattes: http://lattes.cnpq.br/7210778979248931

Fabiano Fraga Carpes - Fabiano_carpes@hotmail.com

Lucia Beatriz Ressel - Ibressel208@yahoo.com.br

Enviado em 03 de novembro de 2015. Aceito em 09 de maio de 2016. 